\title{
Stereotactic radiosurgery in the management of acoustic neuromas associated with neurofibromatosis Type 2
}

Brian R. Subach, M.D., Douglas Kondziolka, M.D., M. Sc., F.R.C.S.(C), L. Dade Lunsford, M.D., F.A.C.S., David J. Bissonette, PA-C, M.B.A., John C. Flickinger, M.D., and Ann H. Maitz, M.S.

Departments of Neurological Surgery, Radiation Oncology, and Radiology, and the Center for Image-Guided Neurosurgery, University of Pittsburgh Medical Center, Pittsburgh, Pennsylvania

Object. Stereotactically guided radiosurgery is one of the primary treatment modalities for patients with acoustic neuromas (vestibular schwannomas). The goal of radiosurgery is to arrest tumor growth while preserving neurological function. Patients with acoustic neuromas associated with neurofibromatosis Type 2 (NF2) represent a special challenge because of the risk of complete deafness. To better define the tumor control rate and long-term functional outcome, the authors reviewed their 10-year experience in treating these lesions.

Methods. Forty patients underwent stereotactic radiosurgery at the University of Pittsburgh, 35 of them for solitary tumors. The other five underwent staged procedures for bilateral lesions (10 tumors, 45 total). Thirteen patients (with $29 \%$ of tumors) had undergone a median of two prior resections. The mean tumor volume at radiosurgery was $4.8 \mathrm{ml}$ and the mean tumor margin dose was $15 \mathrm{~Gy}$ (range 12-20 Gy).

The overall tumor control rate was $98 \%$. During the median follow-up period of 36 months, 16 (36\%) tumors regressed, $28(62 \%)$ remained unchanged, and one (2\%) grew. In the 10 patients for whom more than 5 years of clinical and neuroimaging follow-up results were available (median 92 months), five tumors were smaller and five remained unchanged. Surgical resection was performed in three patients (7\%) after radiosurgery; only one showed radiographic evidence of progression. Useful hearing (Gardner-Robertson Class I or II) was preserved in six (43\%) of 14 patients and this rate improved to $67 \%$ after modifications made in 1992. Normal facial nerve function (House-Brackmann Grade 1) was preserved in $25(81 \%)$ of 31 patients. Normal trigeminal nerve function was preserved in $34(94 \%)$ of 36 patients.

Conclusions. Stereotactically guided radiosurgery is a safe and effective treatment for patients with acoustic tumors in the setting of NF2. The rate of hearing preservation may be better with radiosurgery than with other available techniques.

Key Words * radiosurgery * acoustic neuroma * neurofibromatosis * vestibular schwannoma

Neurofibromatosis Type 2 (NF2) is found both as a sporadic and a genetically transmitted neurocutaneous disorder. It typically afflicts younger patients, and the presence of bilateral acoustic 
neuromas is pathognomonic of the disease. Unlike the solitary, sporadic tumors that tend to displace the auditory portion of the eighth cranial nerve, tumors associated with NF2 tend to form grapelike clusters that often infiltrate and engulf the cochlear nerve.[18] Typical presenting symptoms include gradual sensorineural hearing loss, high-pitched tinnitus, and dysequilibrium. Most tumors manifest modest but erratic growth over time. Management strategies include close observation, surgical resection, and stereotactically guided radiosurgery.[1,4,8,9,11,13,15,26,36,49] Given the bilateral nature of the disease process, preservation of functional neurological status, particularly in regard to hearing, is of paramount importance. Several reports define the outcomes and morbidity resulting from surgical intervention for acoustic tumors in both sporadic and NF2-related cases.[2,3,12,23,37-40,42,43,46-48] In contrast, few studies document tumor control rates and cranial nerve morbidity in patients who undergo radiosurgery. $[9,17,25,29,34,45]$ To assist both patients and physicians in evaluating the risks and benefits of radiosurgery, we reviewed our experience with all NF2-associated acoustic neuromas treated at our center during a 10-year interval.

\section{CLINICAL MATERIAL AND METHODS}

Between August 1987 and October 1997, 40 patients with NF2 (45 tumors) underwent stereotactically guided radiosurgery at the University of Pittsburgh. Thirty-five patients underwent radiosurgery for unilateral tumors, whereas five underwent staged radiosurgical procedures for bilateral tumors. Staged procedures were spaced a median of 28 months apart (range 8-57 months). Twenty-one patients (52\%) were female and $19(48 \%)$ were male, and their mean age was 35 years (range 12-79 years). Thirteen patients (with $29 \%$ of the tumors) had undergone a median of two prior craniotomies for attempted resection of their acoustic neuromas. Eleven patients underwent a subtotal resection and were treated later for tumor progression, whereas two underwent gross-total resection and underwent radiosurgery for recurrence. One patient $(2 \%)$ had received prior fractionated radiation therapy previously, with subsequent tumor growth.

All patients with NF2 presented with bilateral tumors or a unilateral tumor and a family history of the disorder. In patients with bilateral who underwent radiosurgery, each tumor was regarded as an individual for the purposes of outcome analysis. Although there are only 40 patients in the study, we will frequently refer to their overall number as 45 . This is not meant to imply that the tumors themselves had useful hearing or could be assigned a Gardner-Robertson class, but that the signs and symptoms associated with each side in patients with bilateral tumors were documented separately.

All patients demonstrated cranial nerve deficits before radiosurgery. Forty-two tumors (93\%) were associated with some degree of hearing loss. Twenty-four patients were completely deaf on the affected side (Gardner-Robertson Class V). An additional 18 patients maintained some measurable hearing function (Gardner-Robertson Classes I-III) before radiosurgery. Fourteen patients (with $31 \%$ of tumors) experienced facial nerve dysfunction before radiosurgery; nine of these had undergone previous surgical resection. Nine patients (20\% of tumors) had trigeminal sensory loss; three of these cases were attributed to prior surgical resection. Two patients (4\% of tumors) had diplopia related to abducent nerve dysfunction not associated with previous surgery.

\section{Radiosurgical Technique}

The technique of stereotactically guided radiosurgery in which the Leksell Gamma Knife (Elekta Instruments, Atlanta, GA) was used to treat acoustic tumors has been described previously.[26] Briefly, the Leksell model $\mathrm{G}$ stereotactic headframe was affixed to the patient's head after intravenous 
administration of mild sedation and infiltration of the scalp with a buffered local anesthetic agent. Target localization was performed using high-resolution contrast-enhanced multiplanar magnetic resonance (MR) imaging. Computerized tomography (CT) scanning was used before 1991. Since 1992, a specific volume-acquisition MR imaging protocol with 1-mm slices has been used to provide detailed graphic information regarding the tumor and adjacent critical structures and to allow construction of a three-dimensional tumor volume. The images were transferred to the dose-planning computer in the radiosurgery center via a fiberoptic ethernet system. Computerized dose planning was performed initially on a Micro-VAX II workstation (Digital Equipment Corp., Westminster, MA) and later on a Hewlett-Packard workstation running Gamma Plan software (Elekta Instruments). The maximum radiation dose, isodose, and margin doses were determined jointly by the neurosurgeon, radiation oncologist, and medical physicist. Radiosurgery was performed using the 201 source ${ }^{60}$ Co Leksell Gamma Knife (models U or B; Elekta Instruments). On completion of radiosurgery, each patient received a single intravenous 40-mg dose of methylprednisolone.

\section{Radiosurgery Planning}

The mean tumor volume before radiosurgery was $4.8 \pm 0.5 \mathrm{ml}$ (range 0.7-14.7 ml). Multiple isocenters were used in $43(96 \%)$ of the procedures (median six isocenters) to conform the radiation dose precisely to both the intra- and extracanalicular tumor components (Fig. 1). In 44 lesions (98\%), the 50\% or greater isodose line was used to irradiate the tumor margin. One patient had received fractionated radiation therapy previously and was treated with the $40 \%$ isodose. The mean maximum dose delivered to the tumor center was 29.4 Gy (range 18-40 Gy) and that to the tumor margin was 15.1 Gy (range 12-20 Gy). Dose selection was modified according to the estimated risk of radiation-induced complications predicted using the integrated logistic formula and from any history of previous radiation exposure. Other factors considered at the time of dose selection included the tumor volume, history of prior resection, hearing status, and facial nerve function.[8]

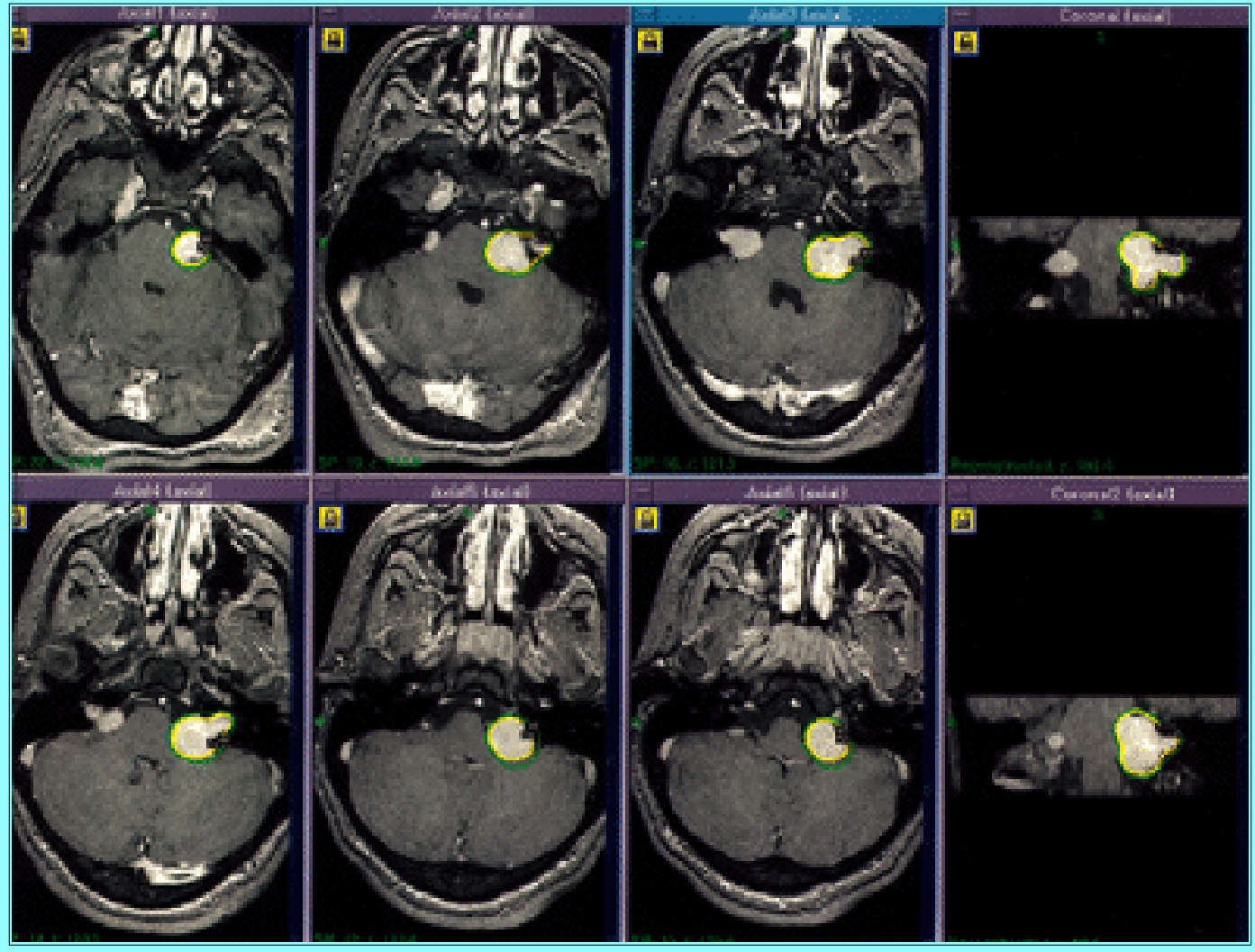


Fig. 1. Axial MR images with coronal reconstructions used in radiosurgical dose planning for a left-sided acoustic neuroma. Seven isocenters were used to conform the dose to the tumor margins. The $50 \%$ and $40 \%$ isodose lines are displayed.

\section{Follow-Up Protocol}

After radiosurgery, patients were requested to undergo clinical examinations and serial neuroimaging studies every 6 months for the first 2 years, annually for the next 3 years, and biannually thereafter. Serial audiograms were obtained at 6- to 12-month intervals in patients with measurable hearing. Contrast-enhanced MR imaging (or CT scanning in cases in which MR imaging was contraindicated) was used to define the tumor response and any peritumoral imaging changes. Each tumor was measured in five separate dimensions (three extracanalicular and two intracanalicular) by using a method previously described.[25] A significant change in tumor size was defined as a difference of $\pm 2 \mathrm{~mm}$. For any patient who lived a significant distance from Pittsburgh, clinical evaluation and imaging were performed by the referring physician and submitted to us for review. Additional clinical follow up was obtained via telephone interview, using an interpreter when necessary.

\section{RESULTS}

\section{Imaging Response}

All 45 tumors were evaluated using postradiosurgery neuroimaging. Over a median 36-month follow-up period (range 6-120 months), 16 (36\%) tumors regressed, 28 (62\%) remained unchanged, and one (2\%) showed progression. In the 10 patients in whom more than 5 years of clinical and neuroimaging follow-up results were available (median 92 months), five tumors were smaller and five remained unchanged (Fig. 2). Loss of central contrast within the tumor was observed frequently and was thought to reflect tumor necrosis. The only patient who demonstrated tumor progression despite radiosurgery was treated early in our experience (in 1988) without the benefit of MR imaging-based planning. This patient ultimately underwent surgical resection. The cumulative tumor control rate was $98 \%$. 

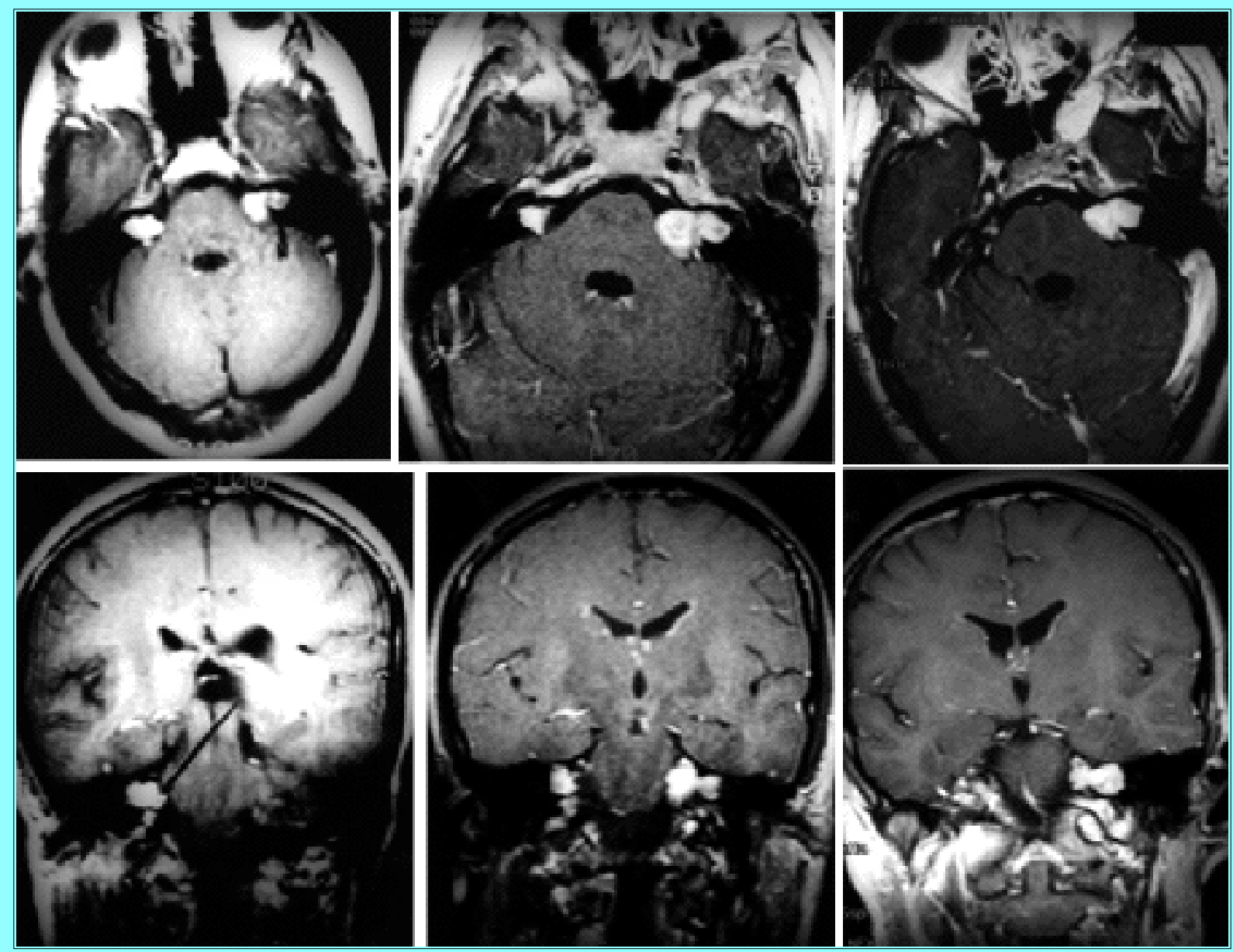

Fig. 2. Serial contrast-enhanced MR images obtained in a 19-year-old woman with NF2 who underwent radiosurgery for a right-sided acoustic neuroma. Upper: Axial images obtained 2 years after radiosurgery (left), 50 months after radiosurgery, demonstrating decreased tumor size (center), and 76 months after radiosurgery with no evidence of right-sided tumor (right). Lower: Coronal images obtained 2 years after radiosurgery (left), 50 months after radiosurgery (center), and 76 months after radiosurgery (right).

\section{Clinical Response}

All patients were actively followed with serial neurological examinations administered by the referring or treating physician. The median period of clinical follow up was 36 months (mean 41.4 months, range 6-120 months). No patient demonstrated improvement on the clinical examination conducted immediately after radiosurgery. Thirty patients (67\%) maintained stable results and $15(33 \%)$ demonstrated clinical deterioration. Two patients (harboring $4 \%$ of tumors) died during the follow-up period secondary to unrelated illnesses. The median Karnofsky Performance Scale score after radiosurgery was 80 (range 50-90). Thirty-five patients (harboring 78\% of tumors) were able to perform normal daily activities at the time of the last examination (Karnofsky Performance Scale score $>=80$ ). Two additional patients (with $4 \%$ of tumors) underwent delayed surgical resection at other institutions; one for progressive hearing loss and one for facial nerve dysfunction, but neither had documented tumor growth on imaging studies.

To document hearing levels, we used the Gardner and Robertson[12] modification of the Silverstein and Norrell hearing classification system. Gardner-Robertson Class I (excellent) and Class II (serviceable) hearing corresponded to an audiogram documenting a pure tone average of less than $50 \mathrm{~dB}$ and a speech 
discrimination score of greater than 50\%. Six (43\%) of the 14 tumors associated with useful hearing at the time of radiosurgery (Gardner-Robertson Class I or II) were unchanged, as were hearing levels during the follow-up period in patients with these tumors (Table 1). Eight patients (with 57\% of these tumors) eventually lost all functional hearing (defined as absent speech discrimination) at a median of 4 months after radiosurgery (mean 5.9 months, range 3-15 months). No patient experienced subjective hearing loss or a documented loss of auditory function within 3 months of radiosurgery.

\begin{tabular}{|c|c|c|}
\hline \multicolumn{3}{|c|}{$\begin{array}{c}\text { OYERALL HEARING PRESERYATION IN } 40 \text { PATIENTS WITH } \\
\text { ACOUSTIC NEUROMAS AND NF } 2 \text { TREATED WITH } \\
\text { STEREOTACTK RADIOSURGER }\end{array}$} \\
\hline $\begin{array}{c}\text { Gardher- } \\
\text { Robertson Class }\end{array}$ & $\begin{array}{c}\text { Preop } \\
\text { (45 tumors) }\end{array}$ & $\begin{array}{c}\text { Postop } \\
\text { (45 tumors) }\end{array}$ \\
\hline 1 & 9 & 4 \\
\hline II & 5 & 2 \\
\hline III & 8 & 2 \\
\hline IV & 0 & 0 \\
\hline$v$ & 23 & 37 \\
\hline $\begin{array}{l}\text { clinical signs ar } \\
\text { ings associated }\end{array}$ & the & $\begin{array}{l}\text { ach tumor tre } \\
\text { individual. } \\
\text { reflect the fir }\end{array}$ \\
\hline
\end{tabular}

In 1992, we began using MR imaging-based radiosurgical planning routinely in patients in whom no contraindications were identified. We also increased the numbers of smaller irradiation isocenters used. By specifically dividing the population into patients who had undergone radiosurgery before 1992 and those after 1992, the difference in hearing preservation becomes apparent (Table 2). Before 1992, five patients with useful hearing (Class I or II) underwent radiosurgery and all of them subsequently lost all speech discrimination. After 1992, nine patients with useful hearing underwent radiosurgery. Six of these patients $(67 \%)$ demonstrated preservation of hearing at their last examination (average follow-up period 25 months).

\begin{tabular}{|c|c|c|}
\hline $\begin{array}{l}\text { OYERALL HEARING PRE } \\
\text { ACOUSTIC NEUROM } \\
\text { STEREOTACTK RAD } \\
\text { YEAR }\end{array}$ & $\begin{array}{l}\text { N } 40 \mathrm{PA} \\
2 \text { TREAT } \\
\text { ACCORI } \\
\text { NTT }\end{array}$ & WITH \\
\hline Gardherfiobertson Class & Preop & Postop \\
\hline pre-1992 (19 tumors) & & \\
\hline I & 3 & 0 \\
\hline II & 2 & 0 \\
\hline III & 5 & 1 \\
\hline iv & 0 & 0 \\
\hline $\mathrm{v}$ & 9 & 18 \\
\hline post-1992 (26 tumors) & & \\
\hline 1 & 6 & 4 \\
\hline ॥ & 3 & 2 \\
\hline ill & 3 & 1 \\
\hline IV & 0 & 0 \\
\hline v & 14 & 19 \\
\hline
\end{tabular}

Thirty-one of the tumors (69\%) were associated with intact facial nerve function (House-Brackmann 
Grade 1) at the time of radiosurgery.[16] Normal function of the facial nerve was preserved in 22 patients (with $71 \%$ of these tumors). Decreased function was observed in nine patients (with $29 \%$ of these tumors) at a median of 5 months (mean 8.2 months, range 4-24 months) after radiosurgery. Of the nine patients who demonstrated worsened facial nerve function, three eventually normalized to Grade 1, five returned to a Grade 2 deficit, and one remained at Grade 3. The preservation rate for normal facial nerve function (Grade 1) prior to 1992 was only 35\%. In patients who underwent radiosurgery after 1992, the rate of normal facial nerve preservation was $84 \%$.

Thirty-six of the treated tumors were associated with intact trigeminal nerve function. Three patients (with $8 \%$ of these tumors) experienced new or worsened trigeminal distribution sensory deficits at a median of 5 months (mean 4.6 months, range 4-5 months) after radiosurgery. One patient subsequently recovered all trigeminal nerve function, whereas two patients had residual deficits. The overall rate of trigeminal nerve preservation before 1992 was $80 \%$. After 1992, the rate improved to $90 \%$.

\section{Evolution of Radiosurgery Dose}

An initial dose of 18 to $20 \mathrm{~Gy}$ to the tumor margin was selected based on the previously reported experience from the Karolinska Institute in Stockholm in treating vestibular schwannomas.[31] Because of an unacceptably high facial neuropathy rate, the dose was subsequently decreased to 16 to $18 \mathrm{~Gy}$ within the first 2 years. By 1992, it was further decreased to 12 to 16 Gy based on our experience with other benign neoplasms and to improve the rate of hearing preservation. In comparing the mean dose delivered to each tumor before and after 1992, a statistically significant difference becomes apparent and may account for the poor rate of hearing preservation before 1992 (Table 3). The mean dose delivered to the margin prior to 1992 was $17.6 \pm 0.6 \mathrm{~Gy}$, whereas the mean dose delivered after 1992 was $13.3 \pm 0.3$ Gy (Student's t-test, $\mathrm{p}<0.0001$ ). The most common tumor size was approximately $15 \mathrm{~mm}$ (extracanalicular diameter) and was treated with a median dose of $12 \mathrm{~Gy}$ delivered to the tumor margin.

\begin{tabular}{|c|c|c|c|c|}
\hline $\begin{array}{r}\text { RAD HTION } \\
\text { WI }\end{array}$ & $40 \mathrm{PATH}$ & $\begin{array}{l}\text { TABLE } \\
\text { 's WITH ACO } \\
\text { DOSURGER' }\end{array}$ & $\begin{array}{l}\text { NEUROMAS A } \\
\text { ORE AND AFT }\end{array}$ & $\begin{array}{l}\mathrm{F} 2 \text { TREATED } \\
992\end{array}$ \\
\hline \multirow{2}{*}{$\begin{array}{c}\text { Gardner- } \\
\text { Roberts on } \\
\text { Class }\end{array}$} & \multirow[b]{2}{*}{$\begin{array}{l}\text { No. of } \\
\text { Tum ors }\end{array}$} & \multicolumn{2}{|c|}{ Mean Margin Dose [Gy] } & \multirow[b]{2}{*}{$p$ value } \\
\hline & & $\begin{array}{l}\text { Pre- } \\
1992 \\
\end{array}$ & $\begin{array}{l}\text { Post- } \\
1992 \\
\end{array}$ & \\
\hline I & 9 & 18.7 & 13.0 & $0.003^{\pi}$ \\
\hline II & 5 & 20.0 & 12.5 & $0.004^{x}$ \\
\hline III & 8 & 16.4 & 12.7 & 0.06 \\
\hline IV & 0 & 0 & 0 & \\
\hline $\mathrm{V}$ & 23 & 17.3 & 13.6 & $<0.0001^{x}$ \\
\hline total & 45 & $17.6 \pm 0.6$ & $13.3 \pm 0.3$ & $<0.0001^{x}$ \\
\hline
\end{tabular}

\section{DISCUSSION}

Patients with NF2 represent a subset of patients with acoustic neuroma who are particularly difficult to treat. Not only are they at risk for complete deafness and other associated functional disabilities caused by bilateral tumors, but many patients also harbor other intracranial neoplasms that may further complicate management. Both the surgeon and patient must carefully consider the risks and benefits associated with each possible management strategy. 


\section{Tumor Resection or Radiosurgery?}

In the setting of NF2, selection of the appropriate treatment for bilateral acoustic neuromas is influenced by a number of factors, including patient age, tumor size, hearing status, and presence of brainstem compression or hydrocephalus. Initial approaches should focus on the prevention or treatment of brainstem compromise and cerebrospinal fluid outflow obstruction. Surgical approaches directed at tumor debulking and decompression are often effective in such cases. Despite the tendency of NF2-related acoustic tumors to invade rather than displace the cochlear nerve, hearing preservation remains second in order of importance. The highest rate of hearing preservation is seen in radiographically stable acoustic neuromas managed conservatively with close observation. Surgical resection via a middle fossa or retrosigmoid approach may accomplish hearing preservation with partial or complete tumor removal. Stereotactically guided radiosurgery may similarly preserve hearing function while arresting tumor growth. However, many specialists in microsurgery consider the continued presence of an acoustic neuroma, despite radiosurgery and lack of documented growth, as a threat to the patient. They are therefore unwilling to accept the attendant morbidity of radiosurgery without the more satisfying result of a postresection imaging study. In dealing with neurofibromatosis, it is often best to view each of the acoustic tumors individually to assess the risks and benefits associated with each treatment option. As mentioned previously, radiosurgery is used to treat small tumors only when progressive hearing loss or growth is documented. Large tumors are treated by resection, with the degree of aggressiveness determined by the extent of preoperative deficit. The overall goal of treatment should provide a balance between preservation of neurological function and tumor control.

To compare adequately the effectiveness of microsurgery and radiosurgery in the treatment of patients with NF2-related acoustic tumors, one must base the results on both the tumor control rate and the rate of cranial nerve preservation. Given the relative paucity of long-term tumor control results in surgical series dealing with NF2-associated acoustic neuromas, we must extrapolate from nonneurofibromatosis series while taking into account the differences in tumor behavior between the two disease processes. In separate articles, two surgeons have cautioned against using intraoperative findings alone, rather than imaging studies, to document completeness of resection. Thedinger, et al.,[44] point out the possibility of unrecognized residual tumor in the lateral aspect of the internal auditory canal, and Neely[31] found residual tumor within the cochlear nerve itself despite apparent gross-total resection. In a series of 16 small, completely resected, intracanalicular acoustic tumors, Samii, et al.,[40] identified no recurrences over a period of follow up ranging from 1 to 8 years. However, Ojemann and Crowell[35] found radiographic evidence of tumor recurrence in three $(0.9 \%)$ of 326 patients between 2 and 9 years after gross-total resection. Two of the patients with recurrence required further treatment. Such studies indicate that smaller and completely resected tumors have a relatively low rate of recurrence.

Complete resection may not always be possible. Large tumors, particularly those associated with contralateral deafness, may be candidates for decompression of the internal auditory canal and subtotal resection, by a method thought to preserve hearing.[14] Because of considerations including advanced age of the patient, their wishes, or contralateral deafness, it is often advisable to perform a subtotal resection to limit operative morbidity in cases of tumor adherence to the brainstem or cranial nerves. Kemink, et al.,[20] identified only one patient with tumor progression among 20 patients (5\%) who underwent subtotal resection and who were followed for a mean of 5 years. Ojemann and Crowell[35] identified significant tumor progression in nine (17\%) of 52 patients who underwent subtotal resection of unilateral acoustic tumors (mean follow up 4.2 years). Seven of the patients required subsequent reoperation, whereas two underwent fractionated radiation therapy. Wazen, et al.,[46] documented tumor 
progression at follow-up times ranging from 6 months to 15 years after subtotal tumor removal in four (31\%) of 13 patients. The rate of tumor progression after subtotal resection in these nonneurofibromatosis series ranges from 5 to $31 \%$ after a minimum of 4 years of follow up.

The seventh and eighth cranial nerves are at risk during acoustic tumor resection. The debilitating effects of iatrogenic hearing loss or facial paralysis must not be underestimated. In most surgical series preservation rates are reported in terms of anatomical continuity and postoperative function. Jannetta,[19] in operating on a group of 605 unilateral acoustic tumors, documented anatomical preservation in $72 \%$ of cases. Ojemann and Crowell[34] stratified facial nerve function based on the size of the resected tumor. For tumors smaller than $1 \mathrm{~cm}$ in diameter, the rate of facial nerve preservation was $100 \%$. For tumors 1 to $2 \mathrm{~cm}$ in diameter, the rate was $96 \% ; 2$ to $3 \mathrm{~cm}, 75 \%$; larger than $3 \mathrm{~cm}, 56 \%$. Ebersold, et al.,[5] in a report on nonneurofibromatosis-related acoustic tumors, noted an anatomical continuity rate for the facial nerve of $93 \%$ (256 cases) with preservation of intact function in 58\%. Samii, et al.,[41] in reporting results from their group of patients with NF2 acoustic neuroma, were able to preserve anatomical continuity in $99(83 \%)$ of 120 cases and Grade 1 facial nerve function in $66(67 \%)$ of 99 cases.

Preservation of hearing remains a more elusive goal. In reporting results of the retrosigmoid approach in patients with nonneurofibromatous acoustic tumors smaller than $2 \mathrm{~cm}$, Ebersold, et al.,[5] noted a hearing preservation rate of $50 \%$. Shelton, et al.,[43] found significant postoperative hearing loss in $56 \%$ of patients who were treated using the middle fossa approach for unilateral acoustic neuromas over a mean follow up of 8 years. Glasscock, et al.,[14] documented a hearing preservation rate of $44 \%$ in 22 patients with bilateral acoustic neuromas who were treated using suboccipital or middle fossa approaches. Mazzoni, et al.,[28] provided longer-term data on their series of 104 patients in whom they had attempted to preserve hearing. The overall rate of tumor recurrence was $8.1 \%$, including five $(10.8 \%)$ of 46 patients followed for 3 to 17 years. Post, et al.,[37] found that four (7\%) of 56 patients in their series had an incomplete resection in which hearing preservation was attempted and that three patients developed regrowth within 3 years. In the largest series, Samii and Matthies[39] were able to achieve complete resections in $98 \%$ of patients and later found recurrence in six of 880 who did not have NF2. Samii, et al.,[41] also reported anatomical continuity of the cochlear nerve in 59 of 100 patients with NF2, with hearing preservation in $36 \%$ ( $57 \%$ with tumors $<30 \mathrm{~mm}$ diameter).

Stereotactically guided radiosurgery has become an acceptable alternative to microsurgery for acoustic neuromas because of a high tumor control rate, low risk of complications, and increasingly longer patient follow up. The two large series from the Mayo Clinic (273 patients) and the University of Pittsburgh (462 patients), in which the use of radiosurgery in the treatment of acoustic tumors is reported, document the safety and efficacy of this management strategy. $[6,22,26]$ Our review represents the largest series to date of neurofibromatosis-related acoustic neuromas treated using radiosurgery. Analysis of previous series identified NF2 and tumor diameter as risk factors for hearing loss in patients with unilateral acoustic tumors who undergo radiosurgery. Hearing loss and cranial nerve dysfunction as complications of radiosurgery are thought to occur as a result of ischemic neuropathy or demyelination arising from radiation exposure.[17] The cumulative tumor control rate and risk of delayed cranial nerve morbidity associated with radiosurgery are similar to those reported in operative series. However, the operative morbidity and mortality rates were significantly lower with radiosurgery.

Given the current rate of hearing preservation (67\% after 1992), we are still cautious about advocating radiosurgery for patients with functional hearing. For patients with large acoustic tumors $(>3 \mathrm{~cm}$ in extracanalicular diameter) and those with progressive neurological deficits secondary to brainstem 
compression, surgical resection (total or subtotal) is the preferred option. We believe that a complete resection should be performed in such patients if possible, but not at the expense of neurological function. We rarely perform radiosurgery in patients with larger tumors because the dose reduction necessary to reduce the rate of adverse radiation-related tissue effects decreases the overall efficacy of the procedure. We typically choose conservative treatment of patients with NF2 who have small acoustic tumors and will recommend radiosurgery or microsurgery only after tumor growth has been documented. We usually encourage patients to learn an alternate means of communication such as lip reading or signing if the tumor in question involves their only hearing side. In certain patients, prior radiosurgery may complicate the treatment of acoustic tumors. Some authors cite radiation-induced fibrosis resulting from prior radiosurgery as a major impediment to surgical resection of acoustic tumors in which progression has been demonstrated.[30] However, our analysis of postradiosurgery resections does not support this concept (Pollock, et al., unpublished data).

\section{Evolution of Technique and Its Effect on Outcome}

Refinements in our radiosurgical technique are the product of continuous review of patient outcome. Our initial experience with acoustic tumors was associated with an approximately $30 \%$ rate of delayed cranial nerve deficits involving the facial or trigeminal nerves.[6,7,24] This finding prompted an average 2-Gy dose reduction to the tumor margin. This seemed to reduce the incidence of delayed cranial nerve morbidity to an acceptable level, although our goal of preserving useful hearing in patients with tumors associated with NF2 remained elusive.[33] This realization again prompted a dose reduction to the tumor margin, which was confirmed in an athymic mouse xenograft model.[27] The results displayed in Table 2 show the clear difference in hearing preservation that occurred after the 1992 radiation dose reduction. Other groups have reported a relationship between cranial nerve deficits and the number of radiosurgical isocenters used in the treatment plan, and our data appear to confirm such a relationship.[17] We use the maximum number of isocenters necessary to conform the dose appropriately to the tumor margins.

In late 1991, we began to use MR imaging-based stereotactic planning. The previous planning technique, which used CT studies, failed to allow adequate visualization of the intracanalicular portion of the tumor. After we confirmed the accuracy and reliability of MR imaging-based planning, we were able to visualize not only the intracanalicular portion of the tumor but also the surrounding neurovascular structures, most importantly the adjacent cranial nerves. Improved imaging allowed for improved dose planning and the use of smaller radiation isocenters to construct a truly conformal dose.[10,21] With these modifications of our radiosurgical technique, the cranial nerve morbidity (in the fifth, seventh, and eighth cranial nerves) associated with NF2-related acoustic tumors dropped considerably. Similarly, our analysis of hearing preservation in patients with NF2 showed significant gains (Table 2). Whereas no patient maintained hearing at a Gardner-Robertson Class I or II level before 1992 (none of five), six (67\%) of nine patients did so after 1992. Most important, radiation-dose reduction and the institution of MR imaging-based planning did not affect the overall observed tumor control rate.

\section{CONCLUSIONS}

Although even longer-term results are desirable to confirm control of growth in acoustic tumors associated with NF2, radiosurgery is an effective alternative to surgical resection. Although the rate of tumor control and reduction in attendant cranial nerve morbidity in neurofibromatosis surpasses that for unilateral acoustic tumors in previously published surgical series, patients with NF2 present unique treatment challenges. The rare occurrence of tumor growth after radiosurgery appears to take place 
within the first 2 postoperative years. Similarly, new or worsened cranial nerve deficits associated with radiosurgery occur within the first 3 years, are usually transient, and are relatively mild in nature. It now appears that the preservation of useful hearing in patients with NF2 is an attainable goal with more sophisticated radiosurgery techniques.

\section{References}

1. Bederson JB, von Ammon K, Wichmann WW, et al: Conservative treatment of patients with acoustic tumors. Neurosurgery 28:646-651, 1991

2. Black FO, Brackmann DE, Hitselberger WE, et al: Preservation of auditory and vestibular function after surgical removal of bilateral vestibular schwannomas in patient with neurofibromatosis type 2 . Am J Otol 16:431-443, 1995

3. Cerullo LJ, Grutsch JF, Heiferman K, et al: The preservation of hearing and facial nerve function in a consecutive series of unilateral vestibular nerve schwannoma surgical patients (acoustic neuroma). Surg Neurol 39:485-493, 1993

4. Comey CH, Jannetta PJ, Sheptak PE, et al: Staged removal of acoustic tumors: techniques and lessons learned from a series of 83 patients. Neurosurgery 37:915-921, 1995

5. Ebersold MJ, Harner SG, Beatty CW, et al: Current results of the retrosigmoid approach to acoustic neurinoma. J Neurosurg 76:901-909, 1992

6. Flickinger JC, Kondziolka D, Lunsford LD: Dose and diameter relationships for facial, trigeminal, and acoustic neuropathies following acoustic neuroma radiosurgery. Radiother Oncol 41:215-219, 1996

7. Flickinger JC, Kondziolka D, Pollock BE, et al: Evolution in technique for vestibular schwannoma radiosurgery and effect on outcome. Int J Radiat Oncol Biol Phys 36:275-280, 1996

8. Flickinger JC, Lunsford LD, Coffey RJ, et al: Radiosurgery of acoustic neurinomas. Cancer 67:345-353, 1991

9. Flickinger JC, Lunsford LD, Linskey ME, et al: Gamma knife radiosurgery for acoustic tumors: multivariate analysis of four year results. Radiother Oncol 27:91-98, 1993

10. Flickinger JC, Lunsford LD, Wu A, et al: Treatment planning for gamma knife radiosurgery with multiple isocenters. Int J Radiat Oncol Biol Phys 18:1495-1501, 1990

11. Foote RL, Coffey RJ, Swanson JW, et al: Stereotactic radiosurgery using the gamma knife for acoustic neuromas. Int J Radiat Oncol Biol Phys 32:1153-1160, 1995

12. Gardner G, Robertson JH: Hearing preservation in unilateral acoustic neuroma surgery. Ann Otol Rhinol Laryngol 97:55-66, 1988

13. Glasscock ME III, Hart MJ, Vrabec JT: Management of bilateral acoustic neuroma. Otol Clin North Am 25:449-469, 1992

14. Glasscock ME III, Hays JW, Minor LB, et al: Preservation of hearing in surgery for acoustic neuromas. J Neurosurg 78:864-870, 1993

15. Gormley WB, Sekhar LN, Wright DC, et al: Acoustic neuromas: results of current surgical 
management. Neurosurgery 41:50-60, 1997

16. House JW, Brackmann DE: Facial nerve grading system. Otolaryngol Head Neck Surg 93:146-147, 1985

17. Ito K, Kurita H, Sugasawa K, et al: Analyses of neuro-otological complications after radiosurgery for acoustic neurinomas. Int J Radiat Oncol Biol Phys 39:983-988, 1997

18. Jääskeläinen J, Paetau A, Pyykkö I, et al: Interface between the facial nerve and large acoustic neurinomas. Immunohistochemical study of the cleavage plane in NF2 and non-NF2 cases. J Neurosurg 80:541-547, 1994

19. Jannetta PJ: Acoustic neurinomas: neurosurgical approaches, in Sekhar LN, Schramm VL Jr (eds): Tumors of the Cranial Base: Diagnosis and Treatment. Mount Kisco, NY: Futura, 1987, pp 563-586 20. Kemink JL, LaRouere MJ, Kileny PR, et al: Hearing preservation following suboccipital removal of acoustic neuromas. Laryngoscope 100:597-602, 1990

21. Kondziolka D, Dempsey PK, Lunsford LD, et al: A comparison between magnetic resonance imaging and computed tomography for stereotactic coordinate determination. Neurosurgery 30:402-407, 1992

22. Kondziolka D, Subach BR, Lunsford LD, et al: Outcomes after gamma knife radiosurgery in solitary acoustic tumors and neurofibromatosis Type 2. Neurosurg Focus 5(3):Article 2, 1998

23. Lalwani AK, Butt FY, Jackler RK, et al: Delayed onset facial nerve dysfunction following acoustic neuroma surgery. Am J Otol 16:758-764, 1995

24. Linskey ME, Flickinger JC, Lunsford LD: Cranial nerve length predicts the risk of delayed facial and trigeminal neuropathies after acoustic tumor stereotactic radiosurgery. Int J Radiat Oncol Biol Phys 25:227-233, 1993

25. Linskey ME, Lunsford LD, Flickinger JC: Neuroimaging of acoustic nerve sheath tumors after stereotaxic radiosurgery. AJNR 12:1165-1175, 1991

26. Linskey ME, Lunsford LD, Flickinger JC: Tumor control after stereotactic radiosurgery in neurofibromatosis patients with bilateral acoustic tumors. Neurosurgery 31:829-839, 1992

27. Linskey ME, Martinez AJ, Kondziolka D, et al: The radiobiology of human acoustic schwannoma xenografts after stereotactic radiosurgery evaluated in the subrenal capsule of athymic mice. $\mathbf{J}$ Neurosurg 78:645-653, 1993

28. Mazzoni A, Calabrese V, Moschini L: Residual and recurrent acoustic neuroma in hearing preservation procedures: neuroradiologic and surgical findings. Skull Base Surg 6:105-112, 1996

29. Mendenhall WM, Friedman WA, Bova FJ: Linear accelerator based stereotactic radiosurgery for acoustic schwannomas. Int J Radiat Oncol Biol Phys 28:803-810, 1994

30. Miyamoto RT, Roos KL, Campbell RL, et al: Contemporary management of neurofibromatosis. Ann Otol Rhinol Laryngol 100:38-43, 1991

31. Neely JG: Is it possible to totally resect an acoustic tumor and conserve hearing? Otolaryngol Head 
Neck Surg 92:162-167, 1984

32. Norén G, Arndt J, Hindmarsh T: Stereotactic radiosurgery in cases of acoustic neurinoma: further experiences. Neurosurgery 13:12-22, 1983

33. Ogunrinde OK, Lunsford LD, Flickinger JC, et al: Cranial nerve preservation after stereotactic radiosurgery of small acoustic tumors. Arch Neurol 52:73-79, 1995

34. Ogunrinde OK, Lunsford LD, Flickinger JC, et al: Stereotactic radiosurgery for acoustic nerve tumors in patients with useful preoperative hearing: results at 2-year follow-up examination. $\mathbf{J}$ Neurosurg 80:1011-1017, 1994

35. Ojemann RG, Crowell RC: Acoustic neuromas treated by microsurgical suboccipital operations. Prog Neurol Surg 9:337-373, 1978

36. Pollock BE, Lunsford LD, Kondziolka D, et al: Outcome analysis of acoustic neuroma management: a comparison of microsurgery and stereotactic radiosurgery. Neurosurgery 36:215-229, 1995

37. Post KD, Eisenberg MB, Catalano PJ: Hearing preservation in vestibular schwannoma surgery: what factors influence outcome? J Neurosurg 83:191-196, 1995

38. Rowed DW, Nedzelski JM: Hearing preservation in the removal of intracanalicular acoustic neuromas via the retrosigmoid approach. J Neurosurg 86:456-461, 1997

39. Samii M, Matthies C: Management of 1000 vestibular schwannomas (acoustic neuromas): surgical management and results with an emphasis on complications and how to avoid them. Neurosurgery 40:11-23, 1997

40. Samii M, Matthies C, Tatagiba M: Intracanalicular acoustic neurinomas. Neurosurgery 29:189-199, 1991

41. Samii M, Matthies C, Tatagiba M: Management of vestibular schwannomas (acoustic neuromas): auditory and facial nerve function after resection of 120 vestibular schwannomas in patients with neurofibromatosis 2. Neurosurgery 40:696-706, 1997

42. Samii M, Tatagiba M, Matthies C: Acoustic neurinoma in the elderly: factors predictive of postoperative outcome. Neurosurgery 31:615-620, 1992

43. Shelton C, Hitselberger WE, House WF, et al: Hearing preservation after acoustic tumor removal: long-term results. Laryngoscope 100:115-119, 1990

44. Thedinger BS, Whittaker CK, Luetje CM: Recurrent acoustic tumor after a suboccipital removal. Neurosurgery 29:681-687, 1991

45. Valentino V, Raimondi AJ: Tumour response and morphological changes of acoustic neurinomas after radiosurgery. Acta Neurochir 133:157-163, 1995

46. Wazen J, Silverstein H, Norrell H, et al: Preoperative and postoperative growth rates in acoustic neuromas documented with CT scanning. Otolaryngol Head Neck Surg 93:151-155, 1985

47. Wiegand DA, Fickel V: Acoustic neuroma--the patient's perspective: subjective assessment of symptoms, diagnosis, therapy, and outcome in 541 patients. Laryngoscope 99:179-187, 1989 
48. Wiegand DA, Ojemann RG, Fickel V: Surgical treatment of acoustic neuroma (vestibular schwannoma) in the United States: report from the Acoustic Neuroma Registry. Laryngoscope 106:58-66, 1996

49. Yamamoto M, Hagiwara S, Ide M, et al: Conservative management of acoustic neurinomas: prospective study of long-term changes in tumor volume and auditory function. Minim Invas Neurosurg 41:86-92, 1998

Manuscript received August 11, 1998.

Accepted in final form December 8, 1998.

Address reprint requests to: Douglas Kondziolka, M.D., M.Sc., F.R.C.S.(C), Department of Neurological Surgery, Presbyterian University Hospital, Suite B400, 200 Lothrop Street, Pittsburgh, Pennsylvania 15213-2582. 